\title{
Survey of Glycemic Control Protocols in Cardiac Surgery Intensive Care Units
}

${ }^{1}$ Vaishali S Badge, ${ }^{2} \mathrm{FM}$ Ashiqe

\section{ABSTRACT}

Perioperative Hyperglycaemia can lead to sepsis, mediastinitis, prolonged mechanical ventilation, cardiac arrhythmias, increased ICU and hospital stay. The different centres follow different protocols to treat hyperglycaemia and still there is a controversy regarding the tight sugar control protocol. This survey was carried out to find the appropriate protocol regarding glycaemic control in various centres in UK.

Keywords: Hyperglycaemia, Sugar control protocol.

How to cite this article: Badge VS, Ashiqe FM. Survey of Glycemic Control Protocols in Cardiac Surgery Intensive Care Units. Res Inno in Anesth 2017;2(1):24-25.

Source of support: Nil

Conflict of interest: None

\section{INTRODUCTION}

Hyperglycemia can occur in patients undergoing cardiac surgery even when glucose homeostasis has been normal in the preoperative period..$^{1-3}$ Morbidity and mortality have been shown to be reduced in these patients following tight control of blood glucose levels using insulin therapy in the perioperative period. ${ }^{3}$

A survey was conducted

- To find out protocols used in cardiac surgery intensive care units (ICUs) to control blood glucose.

- To find the range of blood glucose and $\mathrm{K}^{+}$levels in these units.

\section{MATERIALS AND METHODS}

In this survey, data were collected over telephone from the sister-in-charge and/or the ICU registrar of 36 cardiac surgical ICUs in the United Kingdom (Graph 1). The data included types and number of cases, range of blood glucose levels in ICU patients, insulin protocol for control of blood glucose, maintenance fluid, and range of $\mathrm{K}^{+}$(Graphs 2 to 4 ).

\footnotetext{
${ }^{1,2}$ Consultant Cardiac Anesthetist

${ }^{1}$ Department of Cardiac Anesthesiology, Apollo Hospitals, Navi Mumbai, Maharashtra, India

${ }^{2}$ Department of Cardiothoracic Anesthesia, The Essex Cardiothoracic Centre, Basildon and Thurrock University Hospitals, Basildon, Essex, United Kingdom

Corresponding Author: Vaishali S Badge, Consultant Cardiac Anesthetist, Department of Cardiac Anesthesiology Apollo Hospitals, Navi Mumbai, Maharashtra, India, e-mail: drvaishali_b@apollohospitals.com
}

\section{RESULTS}

- Extended sliding scale: Fixed-dose sliding scales used in the general wards extended into the cardiac ICUs (no bolus)

- Complex sliding scales: Bolus and infusion of insulin as per sliding scale

- Dynamic insulin protocol: Nurse-led tight glucose control based on a separate protocol (Graph 5).

The centers contacted were performing adult, pediatric, and transplantation surgeries with an average of 87 (50-100) cases a month. There were variations in the usage of insulin protocols. We categorized them as extended, complex, and dynamic scale (tight glucose control).

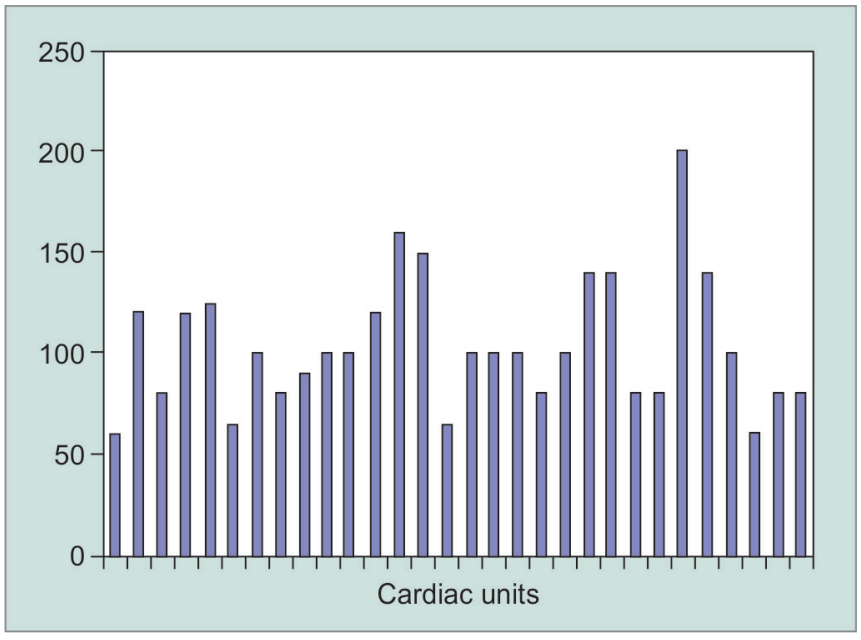

Graph 1: Average number of operations per month

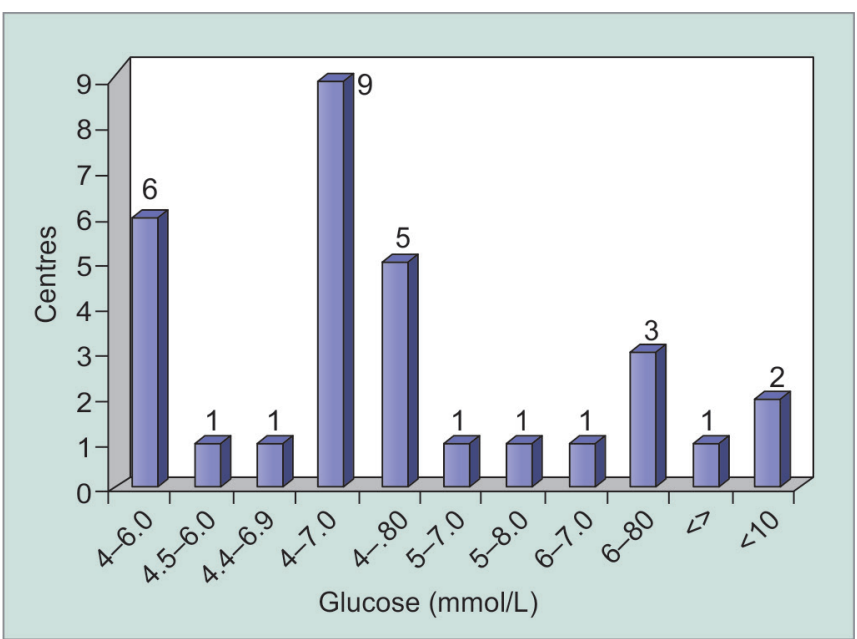

Graph 2: Glucose range 


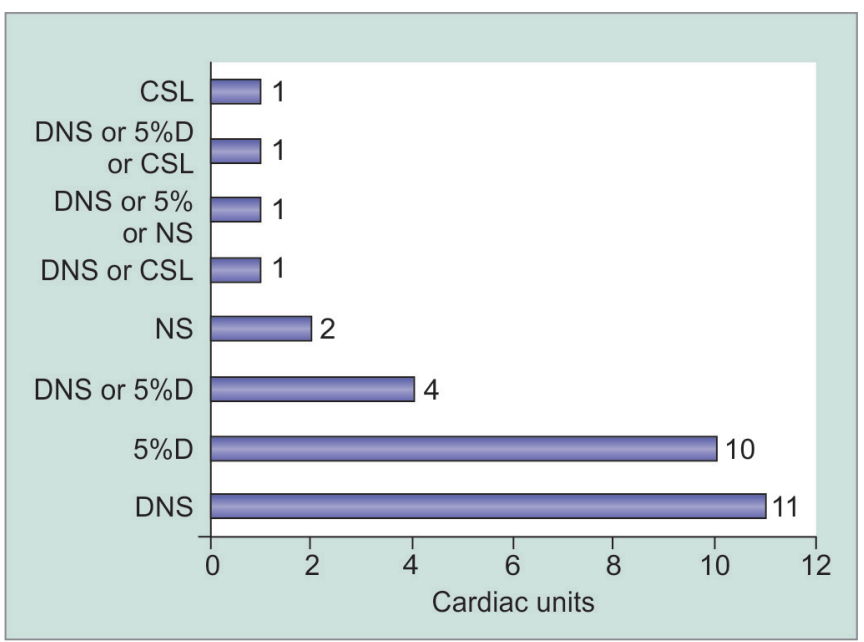

Graph 3: Maintenance fluid

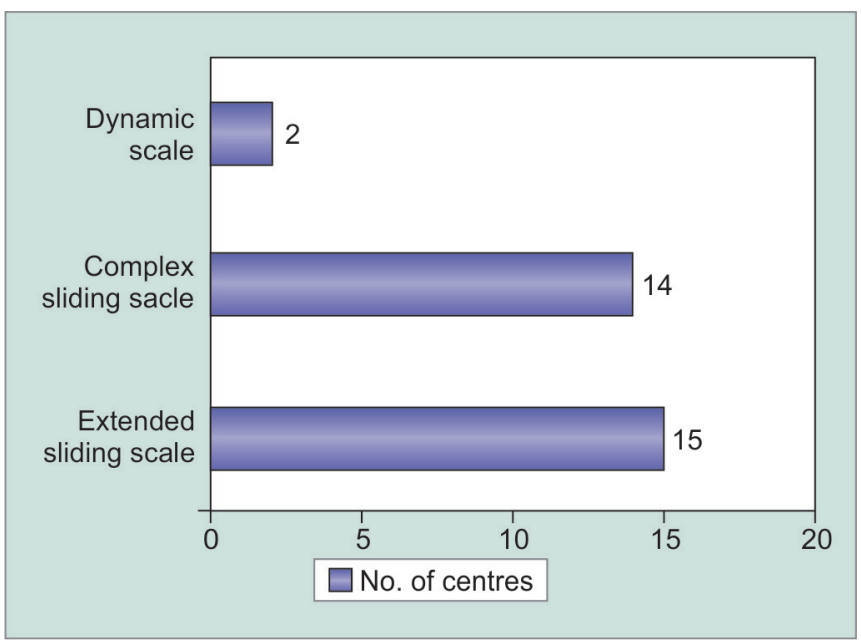

Graph 5: Protocols

Two centers used dynamic scale insulin protocol and the rest had an insulin sliding scale protocol. It was observed that blood glucose was maintained between 4 and $8 \mathrm{mmol} / \mathrm{L}$ in the majority of the centers, with a few centers maintaining glucose below $10 \mathrm{mmol} / \mathrm{L}$. The maintenance fluids used also varied, with a large number of centers using dextrose-based fluids. Potassium was maintained above 4.5 in the majority of the centers (Graph 6).

\section{DISCUSSION}

The in-hospital morbidity and mortality have been shown to be reduced by strict maintenance of normoglycemia. ${ }^{4}$ The tight control of blood glucose rather than higher insulin dose appears to protect against most ICU complications and death. ${ }^{3}$ Although all centers had protocols for glucose control, there were wide variations in insulin regime used and the range of blood glucose being maintained. The maintenance fluid used also

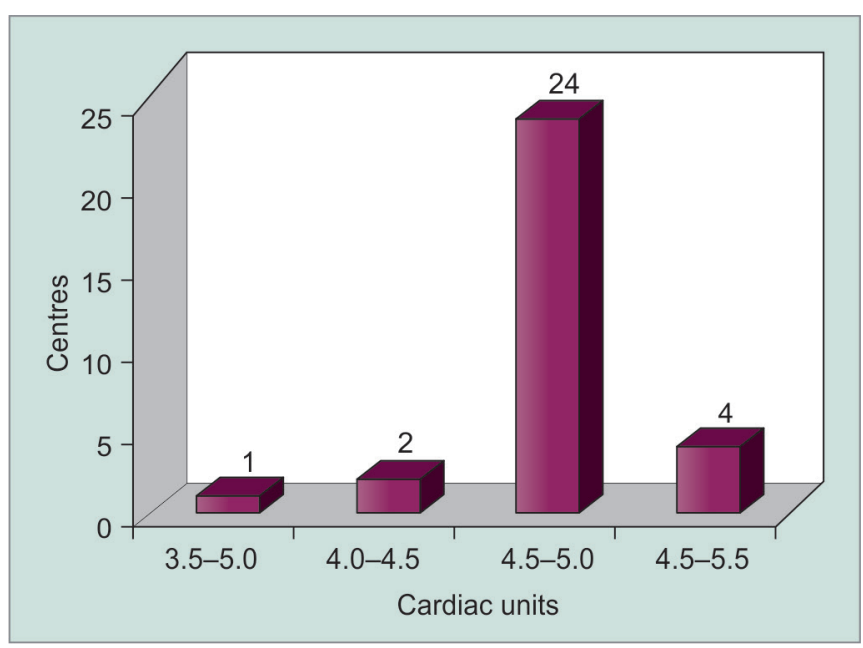

Graph 4: Range of potassium

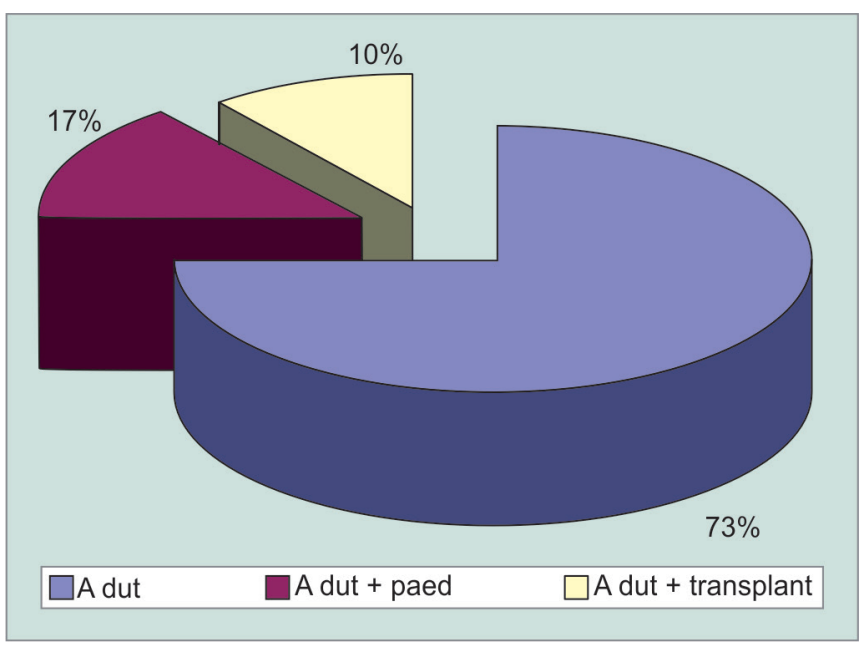

Graph 6: Cardiac surgical centres

varied. However, blood glucose was maintained below $8 \mathrm{mmol} / \mathrm{L}$ in majority of the centers.

\section{REFERENCES}

1. Van den Berghe G, Wouters P, Weekers F, Verwaest C, BruyninckxF, Schetz M, Vlasselaers D, Ferdinande P, Lauwers $\mathrm{P}$, Bouillon R. Intensive insulin therapy in the surgical intensive care unit. N Engl J Med 2001 Nov;354(19):1417-1418.

2. Finney SJ, Zekveld C, Elia A, Evans TW. Glucose control and mortality in critically ill patients. JAMA 2003 Oct 15;290(15): 2041-2047.

3. Van den Berghe G, Wouters PJ, Bouillon R, Weekers F, Verwaest C, Schetz M, Vlasselaers D, Ferdinande P, Lauwers P. Outcome benefit of intensive insulin therapy in the critically ill: insulin dose versus glycemic control. Crit Care Med 2003 Feb;31(2):359-366.

4. Van den Berghe G, Wouters P, Weekers F, Verwaest C, BruyninckxF, Schetz M, Vlasselaers D, FerdinandeP, Lauwers P, Bouillon R. Intensive insulin therapy in critically ill patients. N Engl J Med 2001 Nov;345(19):1359-1367. 